\title{
What is the 'Social' in Climate Change Research? A Case Study on Scientific Representations from Chile
}

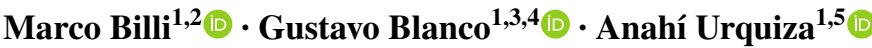

Published online: 11 March 2019

(C) The Author(s) 2019

\begin{abstract}
Over the last few decades climate change has been gaining importance in international scientific and political debates. However, the social sciences, especially in Latin America, have only lately become interested in the subject and their approach is still vague. Scientific understanding of global environmental change and the process of designing public policies to face them are characterized by their complexity as well as by epistemic and normative uncertainties. This makes it necessary to problematize the way in which research efforts understand 'the social' of climate change. How do 'the climate' and 'the social' interpenetrate as scientific objects? What does the resulting field look like? Is the combination capable of promoting reflexivity and collaboration on the issue, or does it merely become dispersed with diffuse boundaries? Our paper seeks to answer these and other related questions using Chile as a case study and examining peer-reviewed scientific research on the topic. By combining in-depth qualitative content analysis of each paper with
\end{abstract}

Electronic supplementary material The online version of this article (https://doi.org/10.1007/ s11024-019-09369-2) contains supplementary material, which is available to authorized users.

Marco Billi

mbilli@alumnos.uai.cl

1 Center for Climate and Resilience Research (CR)2, Av. Blanco Encalada 2002, piso 4, Santiago de Chile, Chile

2 Escuela de Gobierno y Centro de Estudios Modelos de Crisis, Universidad Adolfo Ibáñez, Diagonal Las Torres 2640, Peñalolén, Santiago de Chile, Chile

3 Centro de Investigación en Dinámica de Ecosistemas Marinos de Altas Latitudes, Universidad Austral de Chile, Campus Isla Teja, Casilla 567, Valdivia, Chile

4 Instituto de Historia y Ciencias Sociales, Universidad Austral de Chile, Campus Isla Teja, Casilla 567, Valdivia, Chile

5 Facultad de Ciencias Sociales, Universidad de Chile, Av. Capitán Ignacio Carrera Pinto 1045, Nuñoa, Santiago de Chile, Chile 
a statistical meta-analysis, we were able to: characterize the key content and forms of such literature; identify divisions and patterns within it; and, discuss some factors and trends that may help explain these. We conclude that the literature displays two competing trends: while it is inclined to become fragmented beyond the scope of the 'mitigation' black box, it also tends to cluster along the lines of methodological distinctions traditionally contested within the social sciences. This, in turn, highlights the persistence of disciplinary divisions within an allegedly interdisciplinary field.

Keywords Climate change $\cdot$ Social dimensions $\cdot$ Scientific representations · Chile $\cdot$ Scientific black boxes $\cdot$ Literature meta-analysis

\section{Introduction}

Over the last few decades, the notion of climate change has become increasingly popular, as the most acknowledged manifestation of the contemporary environmental crisis (Estenssoro 2007, 2010). All over the world, urgent calls have arisen to implement long-term policies which may help mitigate its causes and adapt to its consequences (Giddens 2008). In 2015, the representatives of 195 countries met in Paris to negotiate bonding commitments in the fight against climate change (UNFCCC 2016). These are expected to be gradually increased over the next few years, sometimes requiring deep transformations of our present societies (Feola 2015).

As will be discussed in this paper, the present popularity of climate change is due to its gradual transformation into a 'black box' (Bijker et al. 1987; Latour 1987): a socio-technical artefact whose familiarity and naturalization make it readable and readily usable for a broader socio-political audience. This is a necessary precondition for political intervention, but at the same time it prevents us from studying the ontological multiplicity of climate change and its controversial constitutive processes. For a long time, this artefact has been almost exclusively the domain of earth and atmospheric sciences. Consequently, many observations on the 'human' or 'social' aspects of the phenomenon have come either from 'natural' (as opposed to 'social') disciplines or from interdisciplinary, but theoretically heterogeneous perspectives. This resulted in a limited, fragmentary and reductionist definition of what is 'the social' of climate change (Blanco and Fuenzalida 2013; Victor 2015).

In recent years there have been numerous calls to reinforce the presence of social sciences in this field. This perspective is often expected to provide a deeper understanding on both the anthropocentric factors causing climate change, the social determinants of climate impacts and vulnerabilities, and the possibilities for coordinated response to climate threats. Some aspects that have received enhanced attention lately include the interactions between climate vulnerability and adaptation policies (Agrawal et al. 1998), the opportunities and conditions for societal organizations and collective action (Victor 2015) and the role and dynamics of social movements in climate policy (Postigo 2013).

In addition, and especially important for this paper, it is hoped social sciences will shed light on the semiotic processes allowing society to make sense of the 
interaction between itself and nature. More pointedly, there is hope that social sciences may foster a deeper reflection on the very process of climate knowledge creation (Yearley 2009) and on its hidden epistemic (Ulloa 2011a; Aufenvenne et al. 2014) and ontological assumptions (Lidskog 2001; Escobar 2011). This reflection is expected to unveil, among other aspects, the normative notions of 'humanity' underlying climate imaginaries (Chernilo 2017a, b), the transformative potentials dormant within climate action (O'Brien 2012), as well as the boundaries, relationships and possible complementarities among social and natural sciences (Lahsen 2010; Zehr 2015; Brondizio et al. 2016).

While it is urgent to know and do more about climate and global environmental change, beyond the growing popularity of these notions lies the persisting risk that its social and normative aspects are tackled from poorly informed, naive or nonreflexive perspectives. Modern knowledge systems are characterized by multiplicity, complexity and uncertainty (Cornell et al. 2013). Knowledge is at once indispensable, broadly accessible and widely debatable within contemporary society (Nowotny 2003). In this context, it seems increasingly impossible to escape the fluid, valueladen and plural nature of the validity claims to which our 'post-normal' science must subject itself (Funtowicz and Ravetz 2003). Thus, especially for what concerns 'wicked problems' such as sustainable development or climate change (Hirsch et al. 2006; Wiek et al. 2012), more focus should be placed on adopting more transdisciplinary, participatory, reflexive and plural forms of knowledge creation (Spangenberg 2011). These in turn should be geared towards a holistic and integrated understanding of the phenomenon, avoiding the disciplinary and epistemic separations that tend to divide scholars (including those concerning mitigation and adaptation issues: see the section entitled "The Social Sciences in the Construction of Climate Change"). At the same time, scientific knowledge should abstain from seeing itself as external -and implicitly superior- to other forms of representing environmental issues, such as the ones embedded in mass media, public opinion (Billi et al. 2017) or indigenous communities' beliefs (Boillat and Berkes 2013).

Social sciences appear to be in a somewhat privileged position to help foster this kind of paradigm shift in modern science. This is partly because of their intrinsically dual nature, between the 'epistemic' and empirically-founded orientation of positive science, and the universal and theory-driven pretensions of moral philosophy (Chernilo 2011). It is also due to their ability to engage with different combinations of knowledge types (instrumental vs. reflexive) and audiences (academic vs. extraacademic) (Burawoy 2005). No agreement has been reached to date within the social sciences about a singular -or even, plural- manner of defining, giving shape to, and epistemologically approaching their object (i.e. 'the social') (Latour 2007; Giddens 2013). On the contrary, the struggle to define the nature, extent and normative tenure of what constitutes "the social" of a given field is one of the most central and contested issues among social science scholars.

Several questions stem from the previous reflection: what is the field of research emerging from the interpenetration of two blurred and inherently ambiguous 'objects' such as 'climate change' and 'society'? Does this result in a complete fragmentation of the research effort deriving in a variety of different meanings and approaches and thus reducing the chances of purposeful scientific collaboration on 
the matter? Or rather, does some emergent conceptual pattern appear, and in that case, what form does it take?

This paper aims to provide a tentative contribution to answer such questions, through a systematic review, meta-analysis and critical discussion of the scientific representations on 'the social' of climate change contained within research dealing with the Chilean case. We pursue two key objectives: (i) characterizing the main contents and forms adopted by the research on the social aspects of climate change in the country, and (ii) exploring the existence of latent patterns and divisions within such research.

The paper is organized as follows: we first provide a brief historical outline of the international scientific construction of climate change, of the role and influence of the social sciences in it, which will further contextualize our research question (next section). Then, we offer some context on our case study and describe the methods used to tackle it. Subsequently, we present our results and end by summarizing and discussing our main conclusions.

\section{The Social Sciences in the Construction of Climate Change}

The trajectory of climate change as a techno-political artefact can be traced back to the 1960s. In those days the phenomenon was restricted to academic circles and was treated as just another scientific discovery. Gradually, however, it transited through associative processes such as fundraising, conferences, publications and public outreach, aimed at alerting a wider audience of its existence and relevance. Finally, it landed in the spheres of politics and planned socio-technical change, which demanded increasing degrees of international coordination. The discussion of global warming was mutually constitutive of the notion of ecological crisis (Whyte 1967) and environmental crisis (Estenssoro 2007) that were socialized through groups of ecologists and intellectuals. During the 1960s and 1970s these discussions gathered discursive resonance in various summits and international environmental conferences. The World Meteorological Organization [WMO] exerted a key influence in different forums to present environmental changes and the alterations of the climate system as a problem of global importance. These aims required a sophisticated reduction in complexity and uncertainty whilst explaining the phenomenon. Through a long collective effort, the main cause of the issue was finally pinpointed to the increase in the concentration of $\mathrm{CO}_{2}$ and other so-called 'greenhouse' gases [GHG] in the atmosphere (Yearley 2009).

This agreement, however, was only the beginning of one of the most important scientific controversies of the 20th century; whether the GHG increase was to be attributed to natural or anthropic causes (Weart 2010). The Intergovernmental Panel on Climate Change (IPCC) was created in 1988 precisely for the purpose of managing and ultimately resolving this controversy, and it rapidly became a forum for scientific collaboration and the pursuit of interpretative consensus (Agrawala 1998; Hulme and Mahony 2010). While the IPCC operated in the scientific arena, the United Nations Framework Convention for Climate Change (UNFCCC), founded in 1992, dealt with the political side. Over the years, a growing agreement on the 
anthropogenic character of the phenomenon and on its 'mitigation' through concerted efforts to reduce or capture global GHG emissions was reached, thus becoming the central object of intervention (Liverman 2009; Bumpus 2011; Stephan and Paterson 2012).

Progressively, climate change became institutionalized and started to operate as a new black box (Hulme and Mahony 2010; Swyngedouw 2013). Its key concepts quickly outgrew the boundaries of the epistemic communities they had emerged from and were adopted by a wider variety of actors, including scholars within the humanities and social sciences. In fact, by 1996, the International Social Sciences Council created, in association with the International Council of Sciences, the International Human Dimensions Program for Global Environmental Change (IHDP), in order to foster scientific cooperation for a better understanding of the social and human dimensions of the phenomenon (Blanco et al. 2017; ISSC/UNESCO 2013; Mooney et al. 2013). Social sciences' debut in the field ushered in a variety of methods and epistemological points of view, expanding the traditional focus on quantitative models, towards the inclusion of qualitative-based and bottom-up oriented approaches, narratives, imaginaries, perceptions, attitudes, practices, values etc. (Moser et al. 2013).

All in all, however, the influence of social scientists and concepts on the IPCC and the global climate change debate remained weak until the mid-2000s. At that time, two partially contrasting shifts took place. On the one hand, the IPCC's 4th Assessment Report put a definitive end to the controversy on the existence and causality of climate change, sanctioning not only that the phenomenon was indeed happening at an increasing pace, but also that this increase was mainly due to anthropogenic GHG emissions (IPCC 2007). On the other hand, it became evident that climate change was not likely to be fully avoided and thus, societies had to learn to live with (and adapt to) it. Although the notion of 'adaptation' had appeared briefly in the 2nd IPCC report in 1996, it only garnered a political relevance akin to that of 'mitigation' after the Marrakesh Conference of the Parties in 2001, when the United States boycotted the Kyoto Protocol for GHG reduction (Schipper 2006; Basset and Fogelman 2013).

The new spotlight on adaptation, in conjunction with the increasing role played by social sciences in the field, entailed a new conceptual toolbox: notions such as vulnerability, adaptive capacity and resilience, which had been used reservedly in the environmental community, suddenly gathered new popularity (Alexander 2013; Smit and Wandel 2006). At the same time, this fostered a broader reflection on the diverse effects that climate change would produce on a variety of human processes and values. The scholarly and political debate recognized the importance of ethnic, cultural and territorial characteristics in determining climate impacts, and it paid attention to the differential responsive capacities of distinct human groups and communities. Likewise, a new variety of territorially situated and culturally diverse actors entered the field, beyond the governmental and scientific elite actors that had controlled it up until then (Ulloa 2011a; de Olmos 2011; Head and Gibson 2012).

Because of this expansion, we are now witnessing what we may call a 'post-normal' stage of climate change. This stage features a growing criticism and de-stabilization of the institutionalized black box of GHG mitigation and the conceptual 
and practical shortcomings it entails (Demeritt 2001; Liverman 2009; Beck 2010), as well as the ethnocentric conceptions (Ulloa 2011b) and double agendas (Lampis 2013) it is accused of heralding. Such criticism goes hand in hand with an increasing call for the re-politicization of climate change (Ulloa 2011a; de Olmos 2011; Head and Gibson 2012) and enhanced attention to the transformative potential it can offer (O'Brien 2012; Moser et al. 2013; Feola 2015). This stage also coincides with calls from well-known authors (Yearley 2009; Beck 2010; Jasanoff 2010; Lahsen 2010; Orlowe et al. 2012), for a greater involvement of the social sciences in the redefinition of climate change as a political process and for integration with other sciences, as well as the arts and humanities (Rödder 2017). Scholars also began advocating for an experimentation with open and inclusive co-design, co-production and codelivery of knowledge (Moser et al. 2013).

In this context, it is relevant to examine the degree to which the apparent 'hybridization' of climate change when intersecting with 'the social' is effectively opening the field to new objects of enquiry. Likewise, we wonder whether and how the scientific representations on the phenomenon manage to re-create some relatively robust identity for 'the social' of climate change, so that it may be used as a common reference for academic collaboration and interchange. As we will discuss in the rest of the paper, where clear black boxes such as GHG or 'mitigation' are not available, the research community may search for shared meaning through the reference to common methodological or normative positions. Positions that, in fact, are only marginally related to the object itself.

To explore these hypotheses, we now focus on Chile as a case study.

\section{Studying the Social Dimension of Climate Change Research in Chile}

\section{The Chilean Context}

Chile is an interesting case to study because of its peculiar and somewhat contradictory characteristics: on the one hand, it only contributes $0.21 \%$ of worldwide GHG, and emissions per inhabitant are estimated at $5.52 \mathrm{t} \mathrm{CO}_{2} /$ capita, lower than the world average (CAIT 2014). On the other hand, because of its geographical, climatic, and productive characteristics, Chile is considered highly vulnerable to climate change. The 4th Report of the Intergovernmental Panel on Climate Change [IPCC] projected a variety of possible impacts on Chilean territory and socio-economic processes (IPCC 2007). In addition, the country meets 7 out of the 9 criteria established by the United Nations Framework Convention on Climate Change [UNFCCC] to identify potential vulnerability (CONAMA 2008).

More recent research, summarized by the Environment Ministry (2016) and the Centre for Climate and Resilience Research [CR2] (2018) pointed out the high vulnerability of the country's water resources, especially in central and northern Chile where they have already reached maximum usage, leading to an unprecedented event known as a mega-drought (CR2 2015). A combined change in temperature and seasonality makes the agricultural sector one of the most vulnerable to climate change, although such vulnerability varies by region and species and depends on the 
specific coping and adaptive capacity of local actors and communities. Cities are also very vulnerable, both to climate hazards related to extreme weather conditions (particularly flooding and heat waves), and to increasing pollution associated with climate variability and the growing risk of forest fires. The country features a significant biodiversity, which is already endangered by human practices and is therefore becoming less resilient to changing climate conditions. Finally, vital infrastructure and containment facilities are highly exposed to weather-related hazards, including rising sea levels. Relevant impact on other sectors, such as fishing, energy provision and tourism, has also been projected and are currently under study.

Consequently, efforts have been made since the 1990s both to study the causes and effects of the phenomenon and enact policies directed towards its mitigation and adaptation (Environment Ministry 2015). However, this has remained, until recently, a peripheral aspect in the Chilean scientific production, especially regarding its social dimensions. Scientific research on climate change in Chile has mostly come from earth, atmospheric or environmental sciences, such as ecology, geology, physical geography meteorology and marine or terrestrial biology. Social sciences, in contrast, have only had a limited and recent presence in the field.

Research funding mostly comes from the National Commission for Scientific and Technological Research (CONICYT, in Spanish), whose grants are conceded based on peer appraisal of research proposals. Since the said peers are organized in committees on a disciplinary basis, interdisciplinary collaboration is not strongly promoted outside of the few existing explicitly interdisciplinary research centres. Although this situation has been gradually improving, a variety of barriers still exist, especially when attempting to cross the natural-social sciences divide. Moreover, although research on the physical, meteorological and biological aspects of climate change has been performed in several areas of the country, the assessment of human vulnerabilities and other social dimensions of the phenomenon are mostly focused on the central and more densely inhabited areas (CR2 2018).

Chile is also an emerging country, having recently entered the Organisation for Economic Co-operation and Development [OECD] and featuring one of the most market-based (neoliberal) institutional frameworks of all Latin America (Harvey 2005). These characteristics may also influence the way 'the social' is understood. In fact, we think it is important to contrast the common interpretations on the process of scientific construction of climate change (previous section) with the specific modes by which scientists in peripheral countries, such as Chile, give content and meaning to the phenomenon whilst embedding its manifestations within national boundaries.

Only two systematic reviews of the scientific literature on climate change are available for the country: Victoria Team and Lenore Manderson (2011) have examined the health sector, not specifically focusing on Chile, but rather on the $40^{\circ}$ South' (Argentina, Australia, Chile, New Zealand, and South Africa). Pablo Monsálves-Gavilan et al. (2013) review research from natural and social disciplines on the effects of climate change in urban spaces. None of these texts make an exhaustive 
review of the literature related to the understanding of the social dimensions ${ }^{1}$ of climate change. In contrast, we provide a systematic review coupled with a quantitative meta-analysis of the research objects and analytical approaches favoured by the literature.

\section{Methods}

To answer our research questions, we first reviewed the scientific literature on the social dimensions of climate change in Chile, published in peer-reviewed journals between 2010 and 2016, through a mixed qualitative and quantitative analysis, categorizing the texts in terms of topic, methodological approach and argumentative style. For more information on our sampling procedure, please refer to Electronic Supplementary Material I. In total, we reviewed 122 papers, each of which was assigned a univocal ID code. From here on we will reference the analysed texts only through their respective $\mathrm{ID}^{2}$; a full list, complete with bibliographic information of each paper, is available in Electronic Supplementary Material II.

During our analysis, we pinpointed 6 distinct analytical axes along which the literature differentiated itself. Three of these concerned the content or object of analysis: the relative importance given to the determinants of climate or environmental change, or to its effects on specific territories, individuals and groups (topic); the relative saliency and precision assigned to the idea of climate change (centrality) and the definition and role of social processes within the research (perspective). The first variable was inspired from the IPCC-backed distinction between mitigation and adaptation, as discussed in the previous section. The early dominance of mitigation within both scientific and political communications was as important in creating climate change's black box as adaptation was in rupturing the said black box and allowing new actors into the field (including the social sciences). The other two categories were included to identify the degree of fragmentation which may have emerged due to the complex and blurred nature of both the concept of 'climate' and 'social', and their concomitant popularity as catch-all keywords.

Besides the object of research, we were also interested in studying the methodological angle from which the research was initiated and how it was represented to the reader. Social and natural sciences do not always approach their research object or their audience in the same way, so we were interested in looking at the configuration of these aspects at the intersection between social sciences and a research object emerging from the natural sciences. Our basic assumption was that some of the most controversial distinctions within the social sciences may be reflected in the literature we were studying. Two such distinctions are the choice of qualitative or quantitative tools for analysis (methods) and the priority granted to societal macro-structures or micro-realities (approach). A pervasive division remains between those scholars that praise the rigor and replicability of quantitative methods, especially in creating

\footnotetext{
1 Both of these were included in the literature review presented in the "Results" section.

${ }^{2}$ However, please consider that two of the analyzed papers-being themselves analytical reviews of the scientific literature-were already cited in full in the first section and will therefore appear both in Electronic Supplementary Material II and in the reference list at the end of this manuscript.
} 


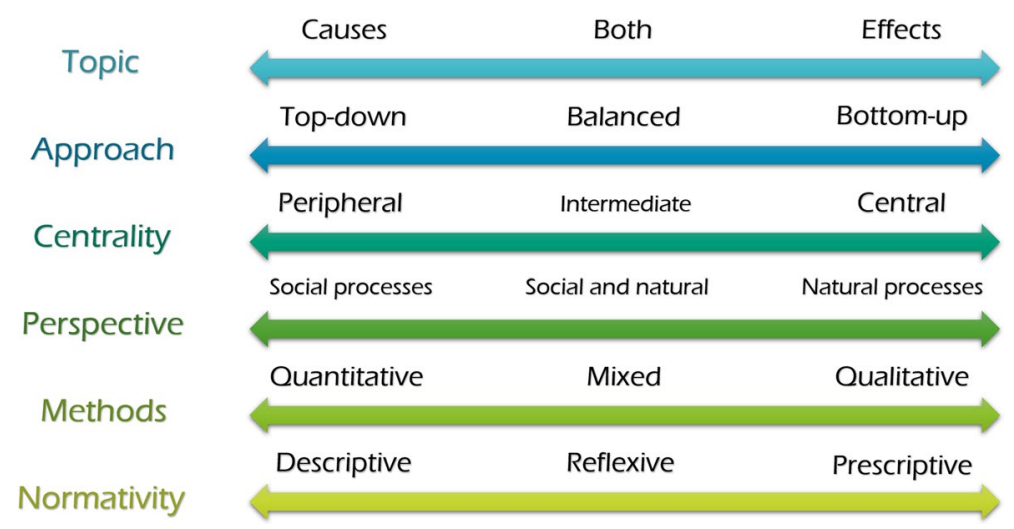

Fig. 1 Analytical axes

relatively generalizable findings, and those that defend the flexibility and detail of qualitative models for describing the whole complexity and contingency of social phenomena (Ragin 2000; Driscoll et al. 2007).

Further controversy surrounds the degree to which social disciplines should mimic natural sciences in trying to produce value-free objectivity, with the risk of hiding the normative positions implicit in the analysist's view behind an alleged objectivity. Alternatively, social scientists may accept that value-based judgments are a constitutive part of both the researcher's perspective and the social processes they observe, with the risk of being unable to distinguish between analysis and prescription. In this context, reflexivity may require a delicate balance between selfoblivious description and self-assured prescription (Chernilo 2011, 2017b): that is the approach we employed in building our last variable, normativity.

Each of these variables was first explored qualitatively, and then codified in the form of a continuum between two opposite and extreme positions (Fig. 1).

While we believe that the 'social' of climate change research could only be fully captured through an in-depth, qualitatively oriented semiotic analysis of scientific literature, we also believe that this analysis could be enhanced - particularly by considering the sample size - through quantitative organization and classification of the data, provided both methods could yield feedback to each other. As we will show in the next section, this approach allowed us to provide a general characterization of the field along the different analytical axes; and to observe how such axes relate to each other. Furthermore, we were able to appreciate the emergence of distinct clusters of research, featuring different ways of delving into the 'social' of climate change. For more details on the analytical procedure we used, see Electronic Supplementary Material I. 


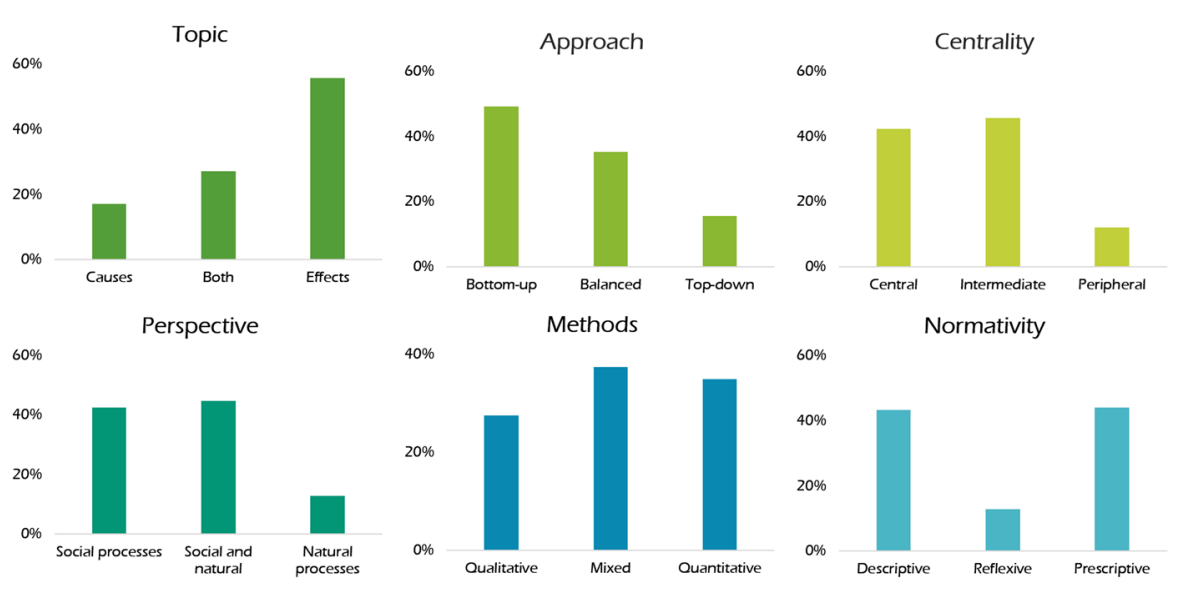

Fig. 2 Descriptive analysis of the analytical axes

\section{Results}

This section describes our results, organized according to their specific objectives: characterizing the main contents and forms of Chilean literature on the topic, and searching for latent patterns and divisions within this literature.

\section{Contents and Forms of the Literature}

The distribution of the analyzed literature along the various analytical axes is shown in Fig. 2.

As displayed in the figure (panel a), a significant part of the literature focused on effects and adaptation, while fewer papers covered causes and mitigation as their object. Most of the latter come from economics or interdisciplinary environmental studies (e.g. Life Cycle Analysis). Interestingly, about a third of the publications seemed to account for both aspects at once. Sometimes, this involved evaluating the general perceptions and imaginaries of certain actors or communities regarding the changes they are experiencing, including their causes and effects. Other papers tackled the suitability of the Chilean institutional framework at facing both mitigation and adaptation challenges brought about by climate change. Paper R2015-20 tries to contextualize efforts to clean up the energy matrix by eliminating wood as a heating source, with a social analysis of the distribution of social vulnerabilities and capabilities in terms of energy access and supply. R2015-27 explores the possible emancipatory effects connected to global change as a space in which an equalizing metamorphosis may be enacted. R2015-17 follows Chile's progress, over the last 30 years, in terms of environmental health. R2013-14 reviews the imaginaries and agential self-attribution of Chilean elites in terms of global climate changes. R2016-27 explores the synergies of urban green architecture, both in terms of carbon sequestration, and of enhancement or urban resilience. Finally, R2012-5 considers the way Chilean mass media views climate change and its causes and effects. 
Through our analysis, we also noticed that some papers, while assuming the climate change label -by using it in their titles or keywords- did not actually grant the phenomenon a key role within their research. Examples may be found in R201516 and R2012-8, where climate change only appears in the abstract, as a source of concern granting further urgency and relevance to what the paper discussed, but it is never mentioned again in the document. The same goes for R2013-1, only mentioning it twice outside the abstract, first in the introduction and then in the conclusions. While other papers are less extreme, they also show a tendency to discuss climate change only as a general context of meaning, which assigns more relevance to threats such as water stress (R2014-11; R2015-2) or extreme climate events (R201616; R2016-28). Similarly, some authors see it as one aspect within the quest for a more secure and cleaner energy provision (R2015-7; R2015-9) and a more sustainable governance of local socio-ecological environments (R2012-4). Of course, this should not be of surprise given the popularity that the notion of climate change has been gaining within a wide variety of scientific communities. As automated search tools gain popularity as a way of accessing scientific research, it becomes more of a common practice for authors to insert a catchy concept within their abstract or keywords, in the hope of maximizing their paper's visibility. Fortunately, this superficial use of the concept of climate change is not the norm: panel $b$ shows that over $42 \%$ of the analyzed papers do have climate change as a main topic. Another $45.6 \%$ address it as an especially relevant aspect within the analysis, while stressing the need to study it in connection with other problems, such as pollution, risk management, urban management, water or energy policy, global environmental change, socio-ecological resilience etc.

Similar considerations apply to 'the social'. Various papers, most of them from the environmental sciences (R2010-4; R2011-3; R2012-12; R2013-4; R2016-10), tackle 'social' aspects of the issue only in terms of a broad -and usually quite superficial- critical review of the legal and institutional framework for the management of natural resources in the country. Often this is coupled with a strong demand for better and more environmentally-responsible initiatives. Again, it is unsurprising that authors untrained in the social sciences do not appear particularly prone to deep theoretical or empirical refinement about what the 'social' means when studying climate change. Nevertheless, such a peripherical position for 'the social' was found to be quite rare. While roughly 4 out of 10 papers focus on social aspects (panel c), it exceeded our expectations, given the recent entrance of social sciences into the field. Most of the papers granting a central role to 'the social' come from core social science disciplines, especially from sociology, anthropology, psychology, or even philosophy and ethics (R2015-22). Other papers try to bridge the gap between social and 'natural' aspects of the problem. Often, this occurs through the collaboration of social scientists with scholars from earth, atmospheric and environmental sciences. In fact, engineering and economics appear to be the most prone to this kind of collaboration. Alternatively, these papers may come from disciplines which are themselves on the boundary between social and natural sciences: geography being a paradigmatic example of this.

Geographical publications are among the most likely to combine quantitative and qualitative methods. For instance, they often link the history of institutions and 
legislation with the analysis of economic trends, and the mapping of geo-physical features (R2010-1). Likewise, they articulate climate models with political ecology (R2013-18), surveys and in-depth interviews (R2016-16), satellite imagining and census data (R2014-5), biogeographical and socio-economical time series with the analysis of public policies (R2013-7) and local perceptions (R2012-11), as well as climate projections and ethnographic methods (R2010-7). In other instances, they adopt mixed-method designs, such as geometrical mapping (R2015-8), or interdisciplinary case studies (R2012-9; R2016-1).

Other papers, especially those situated in the 'social processes' panel, tend to focus on qualitative approaches, including ethnography (R2011-2), genealogical analysis (R2013-24; R2016-3), critical review of public policies (R2016-18), comparative case studies (R2016-12; R2016-20; R2016-25), theoretical-methodological reflections (R2016-5), or argumentative essays (R2012-2; R2015-22). On the other hand, the main quantitative methods included statistical regressions (R201210), simulations (R2015-28), Life Cycle Analysis (R2015-3) and the construction of numerical indexes of climatic risk (R2016-11). Models were also found to be very common, either regarding agent behaviour (R2016-23), hydrographical processes (R2014-1), macro-economic trends (R2011-1), or a mixture of the latter two (R2016-8). Overall, the literature is evenly divided between qualitative and quantitative methods, with a somewhat lower (27.6\%) presence of the former (Fig. 2, panel d). This was unexpected, since we had assumed qualitative approaches would dominate the study of 'the social'. As we will discuss below, however, both methods feature different ways of formulating the problem.

Likewise, it is worth noting that almost half (49.2\%) of the papers employ a bottom-up approach: that is, they centre on actors' perceptions, attitudes, behaviours, practices and imaginaries, rather than observing or modelling structural and macroprocesses (Fig. 2, panel e). This was expected, since it is consistent with the preferred viewpoint of various disciplines of the social sciences (psychology, anthropology, and partly economics). The tension between the top-down and bottom-up perspectives is particularly strong within the study of climate vulnerabilities and governance mechanisms, where it is associated with political tension between centralized steering and local autonomy. In this sub-field, bottom-up approaches tend to be particularly active in deliberately criticizing top-down ones, for their allegedly reductionist understanding of social processes (R2010-7; R2015-15). Also, we frequently observed $(35.2 \%)$ attempts to balance the attention of macro-processes and micro-realities, combining models, maps, literature analysis or theoretical discussion with participatory methods, interviews, ethnographies and surveys. Often, papers following this approach explicitly state their intention of connecting these two extreme positions, in order to acknowledge the diversity and complexity of the climate phenomena (R2014-2; R2014-12; R2015-18; R2015-19).

Our final distinction concerns the degree of normativity in how the research is communicated to its audience. In this sense, we could classify a relatively small number of papers as properly reflexive (Fig.2, panel f). Of course, that might be due to us putting too high a standard for reflexivity, but it is worth mentioning that many publications explicitly classified themselves in either extremity of this axis. Some stated their intent of offering a purely descriptive and instrumental depiction 


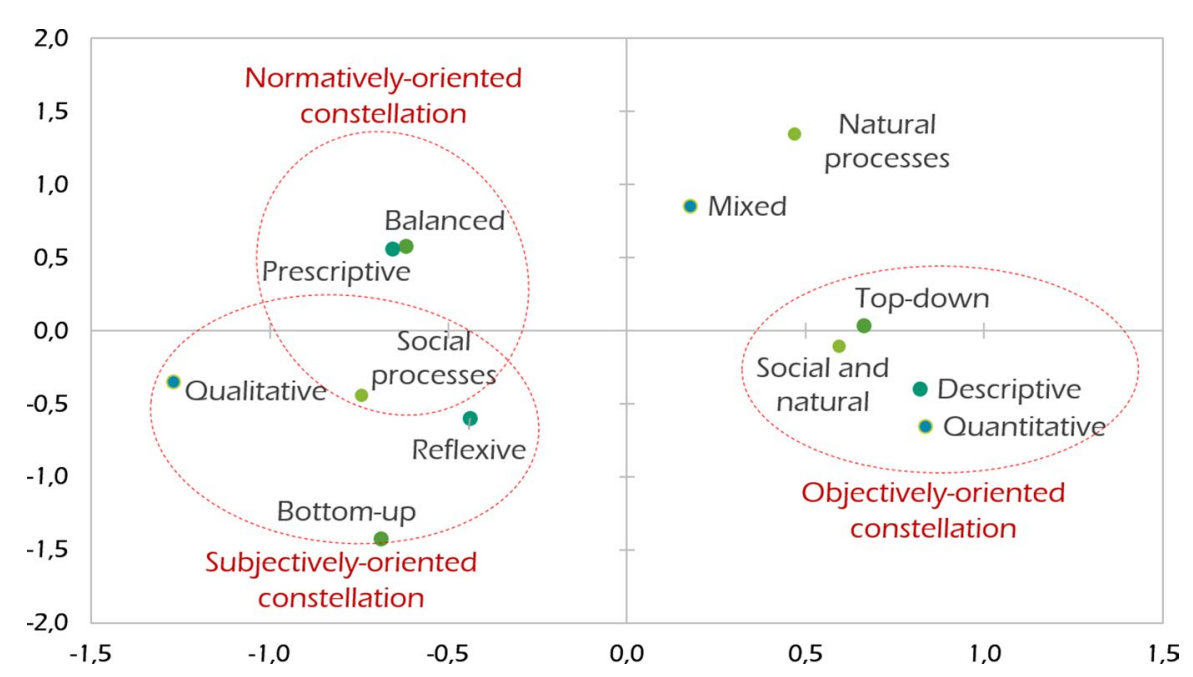

Fig. 3 Correspondence chart

of reality as-is, in order to generate more information for external and independent decision-making processes (R2013-13; R2013-6; R2016-7; R2016-9). Other papers endeavoured to provide a prescriptive and deeply normative affirmation of how reality should -or should not- be (R2011-2; R2012-2; R2015-22). In the middle, we found a variety of approaches attempting to introduce reflection in their description, or to self-reflect on the normative assumptions of their positions. Approaches calling for more transdisciplinary work to improve sustainability, adaptation, and equal inclusion in decision-making (R2013-19; R2014-5; R2015-4; R2016-5) are interesting. However, they often do not provide an explicit argumentation of the normative position contained in their very subscription of sustainability, adaptation, or equality.

Aside their direct value as a form of characterizing the existing literature on the topic in Chile, the previous observations induced a few preliminary hypotheses regarding the emerging structure of the field. First, that there is a correlation between the choice of topics, approaches and normative orientations. Secondly, that based on this correlation, a useful and grounded classification of the literature may be possible. This seemed relevant given our initial research questions, since it would provide an outlook on latent patterns and divisions structuring the field beyond the IPCC-backed distinction between causes and mitigation on the one hand, and effects and adaptation on the other. To test these hypotheses, we proceeded to the quantitative meta-analysis of the sample literature described in the following section.

\section{Visualizing Latent Patterns in the Literature}

To explore the interrelations between the previously mentioned variables, we first used Correspondence Analysis, a statistical technique which allows us to visualize the association between distinct categories of different variables (see Electronic 
Table 1 Cluster profiles

\begin{tabular}{|c|c|c|c|c|c|c|c|}
\hline $\mathrm{Cl}$. & \# & Topic & Approach & Centrality & Perspective & Methods & Normativity \\
\hline 1 & 23 & Causes & Top-down & Central & Social processes & Quantitative & Descriptive \\
\hline 2 & 25 & Effects & $\begin{array}{l}\text { Top-down/ } \\
\text { Balanced }\end{array}$ & $\begin{array}{l}\text { Central/ } \\
\text { Intermediate }\end{array}$ & Social and natural & Quantitative & $\begin{array}{l}\text { Reflexive/ } \\
\text { Descriptive }^{*}\end{array}$ \\
\hline 3 & 42 & Effects & $\begin{array}{l}\text { Balanced/ } \\
\text { Bottom-up }\end{array}$ & Intermediate & Social processes & Qualitative & Prescriptive \\
\hline 4 & 23 & $\begin{array}{c}\text { Effects/ } \\
\text { Both }\end{array}$ & Top-down & Intermediate & $\begin{array}{l}\text { Social processes/ } \\
\text { Social and natural }\end{array}$ & $\begin{array}{l}\text { Qualitative/ } \\
\text { Mixed }\end{array}$ & $\begin{array}{l}\text { Reflexive/ } \\
\text { Prescriptive }^{*}\end{array}$ \\
\hline 5 & 5 & Effects & Bottom-up & Peripheral & Interdisciplinary & Quantitative & Descriptive \\
\hline 6 & 4 & Causes & Top-down & Peripheral & n.a. & n.a. & Prescriptive \\
\hline
\end{tabular}

*Only a few papers could be properly considered 'reflexive'; however, since the category was placed roughly in the middle of a descriptive-prescriptive continuum, we could identify partly reflexive papers both on the descriptive and the prescriptive side

Supplementary Material I). The analysis shows a strong association between four variables: Approach, Perspective, Methods and Normativity (Fig. 3).

In Fig. 3, we may appreciate three distinct constellations, each representing a different way of framing research on 'the social' of climate change. For easier comprehension, we suggest a distinctive label for each of them. However, one must keep in mind that these are not clear-cut and mutually-excluding typologies, but rather possible constellations through which 'the social' of climate change can be represented.

Studies trying to build a bridge across natural and social processes tend to be quantitative, from a top-down approach, and strongly descriptive in character (we will label this constellation 'objectively-oriented'). On the other hand, studies featuring a dominant prominence of social processes can follow two different strategies: the first is eminently qualitative, usually adopting a bottom-up approach and tendentially more reflexive ('subjectively-oriented'). Other papers follow a second strategy, which tends to balance bottom-up and top-down approaches and to present results in a more prescriptive fashion ('normatively-oriented'). The latter two categories (balanced approach and prescriptive normativity) can also be employed in studies using a mixed, rather than qualitative, approach. In that case, however, it is also more likely that the paper will have a stronger focus on natural processes than on social ones. The category 'natural processes' appears rather isolated, which is a joint consequence of its being less associated with other categories and of the relatively reduced number of articles that were classified within it.

Having confirmed the association between the variables, we tested their use in classifying the papers included in the sample. Although the previous analysis proved a significant association between only 4 out of the 6 variables, there was no reason to exclude the other 2 from the classification attempt, so we decided to include them. For these effects, we used a Cluster Analysis (see Electronic Supplementary Material I), which allowed us to divide the sample into 6 distinct clusters. Table 1 shows the profile of each cluster along the 6 variables. 
Except for the last 2 clusters (very peripheral, and with more emphasis on the natural sciences), we observe 3 clusters whose main topics are the effects of climate change, while only one is dedicated to its causes. This is consistent with the greater role that effects play in the sample topics. Cluster 4 also concentrates most of the studies which cut across the cause-effect dichotomy.

In the following sections, we examine each cluster in order to describe in further detail the type of papers it includes. We discard the last two clusters since the papers they include are few and peripheral with respect to climate change and its social dimensions. For this characterization, we used the results of our previous qualitative and quantitative analysis, but we also performed a new in-depth qualitative content analysis of the full text of the paper when that was needed. Bracketed numbers indicate frequency of the cluster or sub-cluster in the sample. The results confirm that the papers tend to group along the lines of traditional social science divisions (e.g. approach, perspective, methods and normativity). However, while clusters 1 and 2 are visibly dominated by the objectively-oriented constellation, the subjectively- and normatively-oriented articles appear more interchangeable (especially within clusters 3 and 4). This is consistent with the latter constellations appearing relatively close one to the other in Fig. 3, if compared with the objectively-oriented one.

\section{Cluster 1: Causes and Mitigation of Climate Change [23]}

The main feature of this cluster is its primary focus on causes and mitigation; it can be divided into 3 sub-clusters:

- Quantification of pollutant emissions and other environmental impacts of human activities [9]: mainly energy, but also waste management, construction and agricultural production; methods include Life Cycle Analysis, econometrics and environmental accounting.

- Macroeconomic modelling [8] of the effectiveness and secondary impacts of economic policy instruments (e.g. carbon taxes) aimed at reducing GHG emissions, including general equilibrium models and econometrics, as well as the review of existing methods and approaches on the subject.

- Evaluation of public policies related to the mitigation of climate change [6], including the description and assessment of existing instruments in Chile -sometimes in comparison with other countries- and quantitative evaluation of opportunities and barriers to such policies -e.g. propensity to pay for NCRE, representations of climate change in student elites, and consumer preferences regarding carbon footprint information.

Most of these papers view causes and mitigation with an almost exclusive attention to social processes, quantitatively and with a top-down approach, and usually adopt a descriptive orientation (objectively-oriented). Also note that most of the cluster is dominated by economics. 


\section{Cluster 2: Responsive Capacity to Climate Threats [25]}

As opposed to causes and mitigation, effects and adaptation can be studied in three different ways: papers in Cluster 2 resemble those of Cluster 1, and thus are markedly quantitative and descriptive. However, they are more prone to balancing topdown and bottom-up approaches in the form of strongly locally-oriented models and maps, which also makes them tendentially more reflexive. Papers within this cluster also tend to mix more than one discipline, from both social disciplines (primarily geography, sociology, economics, engineering and psychology) and natural ones (hydrography and engineering). 2 sub-clusters can be distinguished:

- Quantitative assessment of vulnerability [16], primarily of water resources -combining hydrographic models with economic supply-demand ones- or urban settlements -comparing satellite maps with census data and urban fragmentation, sometimes adding surveys or participatory tools to account for perceptions and effective responses.

- Rational-agent-based modelling [7] of farmers and other agents to climate threats, primarily water scarcity, sometimes also using surveys to gather information on perceptions and climate awareness of actors.

To these we must add one study based on a survey on the experiential effects of climate change, and one on its coverage in Chilean mass media.

\section{Cluster 3: Climate Change Effects and Adaptation [42]}

This third cluster - and largest_-includes research on the effects of climate change, vulnerabilities and possibilities for adaptation, agglutinating both the subjectivelyand normatively-oriented constellations, with a stronger emphasis on the latter. These papers tend to focus on perceptions and bottom-up imaginaries, or to balance them with top-down modelling. The analysis is qualitative and often prescriptive. This is also one of the clusters with the largest presence of papers focusing on 'pure' social processes. Specifically, 3 sub-clusters can be identified:

- Risk, vulnerability and climate resilience conditions of different groups, communities or social systems [18], distinguishing between urban areas -focused mainly on health problems, extreme events and green infrastructure- and rural ones -where the relationships between water resources, agriculture and community self-organization are the main topics.

- Strategies and instruments for adapting to climate change [18], primarily in terms of urban planning, water management, coastal systems, and technology; a markedly interdisciplinary and participatory focus is common.

- Perceptions and representations regarding climate change and its effects [6], including ethnographies, qualitative interviews with local actors and stakeholders and genealogical analysis. 
Conceptually, these studies tend to adopt perspectives from sociological critical theory, social anthropology and political ecology: among the most commonly emphasized topics are the promotion of participatory approaches, a critique of the existing institutional framework and an emphasis on situations of double exposure to both environmental and social changes, the latter being often identified with modernization, globalization and capitalism.

\section{Cluster 4: Reflections on Society, Policy, and the Climate [23]}

This last cluster is quite peculiar, as it is the only one displaying purely top-down approaches: secondary and/or documental analysis is common (sometimes from an historical perspective), along with theoretical reflections and literature reviews. This research tends to integrate both social and natural processes, using either qualitative or mixed methods: this is the cluster with the highest concentration of reflexive papers, although it also gives some space to prescription and recommendations. In our Correspondence Analysis, Cluster 4 would have been placed somewhere near the intersection of the axes of Fig. 3.3 sub-groups can be identified:

- Assessment of public policies [11], with a strong focus on adaptation, either from a sectorial standpoint -focusing on water and health- or from an allegedly 'integrated' point of view -which, however, tends to substitute such distinctions with another, between urban and rural spaces.

- Theoretical-methodological reflections on vulnerability [7], reviewing the state of the art and often proposing improved frameworks, indicators or indexes.

- Critical reflections on recent trends in national and regional policy [5], mostly coming from non-social disciplines such as ecology, marine biology or atmospheric sciences.

\section{Discussion and Conclusions}

As we established in "The Social Sciences in the Construction of Climate Change" section, the scientific trajectory of climate change underwent a careful and complex process of complexity-reduction aimed to transform it into a 'black box', particularly revolving around the idea of 'mitigating' GHG emissions. Lately, however, the convergence of three processes -the growing importance of adaptation and transformation, the engagement of the social sciences, and the extension of the field to a wider variety of actors- may be in fact triggering a centrifugal trend within climate change research that tends to multiply and fragmentate it into different disciplinary and epistemological communities. These communities rarely interact; while climate change itself becomes more of a 'boundary object' (Star and Griesemer 1989) bridging said communities rather than an actual researchable object, at least in its 'social' dimensions. As the very idea of 'boundary object' suggests (Star 2010), this might result in opening the black box to a broader discussion, or it might just end up in the rhetorical inflation (and thus emptying) of the concept of climate change. Which alternative prevails mainly depends on the ability of research communities to reconstruct 
some relatively robust local representation of both 'climate change' and 'the social' in a way that may serve their specific research interests while also maintaining -and slowly transforming- the key elements that support the popularity of such notions as shared references for the whole research arena.

To understand the form taken by the scientific representation of the intersection between 'climate change' and 'the social', we examined the Chilean case and reviewed, both qualitatively and quantitatively, the scientific literature on the topic. Our goal was double: characterizing the main contents and forms of such literature; and searching for latent patterns and divisions.

Our first result shows that a relatively low number of papers focus on the causes and mitigation of climate change. Moreover, the area is almost totally monopolized by economics and environmental sciences, other social sciences being mostly absent. This may partly be explained by Chile's low contribution to climate changerelated emissions and high vulnerability to its effects ("The Chilean Context" section). In any case, it is an interesting result since causes and mitigation configure precisely the research area where, as shown in "The Social Sciences in the Construction of Climate Change" section, the black box of climate change is most firmly established. Thus, 'the social' of climate change seems to develop in the investigation of effects, vulnerabilities and responsive capacities, or even in destabilizing the IPCC-led separation of tasks between mitigation and adaptation. This can either occur by noting the synergies and interdependencies between the two aims; or it may involve explicitly reflecting on the need to tackle the problem -and its management- as a whole.

Thus, while the distinction mitigation/adaptation plays a role in structuring the field, it is clearly not the only important attribute. The methodological approach and framing of results appear to be equally important in understanding the scientific representation of 'the social' of climate change, at least in Chile.

Interestingly, papers focusing on causes or mitigation tend to be more homogenous in this respect, and adopt a tendentially quantitative, descriptive and top-down form (what we called objectively-oriented constellation). The dominance of economics within the cluster must play a role in this.

Consistent with the historical pattern discussed in "The Social Sciences in the Construction of Climate Change" section, most social sciences only limit their presence to the area of effects or adaptation, and that is also where the most heterogenous framing of 'the social' is observed. Three major divisions are evident, all representing highly disputed tensions within the social sciences: the primacy given to modelling and observing general patterns from above (top-down approach), or to highlight the complexity and idiosyncrasy of specific societal processes and contexts (bottom-up approach) and the choice of method (qualitative or quantitative), as well as the tendency to produce purely-descriptive and value-free data, or prescriptivelyoriented assessments (normativity).

At least three constellations of 'the social' of climate change are manifested along these axes: Cluster 3 is focused on the social impacts, meanings and practices adopted by different actors and communities when confronted with issues related to climate change. Moreover, it is tendentially bottom-up, qualitative and prescriptive. Cluster 2, while having similar aims, tends to be top-down, quantitative and 
descriptive, centred in modelling coupled socio-ecological vulnerabilities and human responses to climate change. Cluster 4 stands somewhat in the middle, adopting a more reflexive stance and mixed methods, although solely from a top-down perspective (usually employing secondary or documental data). This cluster, in fact, is also the one which tends to cut across the cause-effect dichotomy more often, although this was also observed within Cluster 3.

It is interesting to compare our typology with previous attempts at classifying the 'social' of climate change. Zehr (2015) and Blanco and Fuenzalida (2013), by focusing mainly on the explicit topic of research papers, proposed four ways by which 'the social' and 'the climate' could be linked: how society causes climate change; how the latter impacts society; associativity and responses; and semiotic representations of climate change. While we also observe some separation between causes and effects, this is far from being as clear-cut as it may be expected given the importance the IPCC places on such distinction. Moreover, when the lens is moved from the contents of the research and publications to their form, quantitative, top-down and descriptive studies tend to cluster together regardless of whether they focus on cause-mitigation, or effect-adaptation. Conversely, a very large group of papers, almost all of which are focused on effects-adaptation, are qualitative, bottom-up and prescriptive. Finally, we observed an emerging attempt at reflecting upon the very relationship between society and climate.

Moreover, we also noted that qualitative and bottom-up papers tend to have a stronger focus on social processes. On the contrary, top-down and quantitative works are mostly used in conjunction with attempts to bridge the natural-social divide. Similarly, quantitative and top-down approaches appear to be more open to insert qualitative and bottom-up considerations in the analysis than the other way around. More in-depth analysis showed this to be related to a persisting disciplinary division: despite the interdisciplinarity of the subject, economics is one of the disciplines with a stronger presence in the field, especially in the mitigation and modelling sub-fields, and is most prone towards quantitative, top-down analysis. It is also one of the disciplines open to cooperating with non-social sciences. Geography papers residing on the border between the social and natural science and seem comfortable with quantitative and top-down approaches, but they tend to be more prone to combining it with more bottom-up and qualitative assessments. Anthropology, a good part of sociology and psychology are characteristically bottom-up and qualitative, and the least prone to delve outside the field of pure social processes. Another segment of sociological research, history and law tend to perform the most reflexive approaches, but from a birds-eye view.

Furthermore, studies with similar theoretical backgrounds tend to fall into the same cluster. For example, within the social sciences, papers adopting tools from sociological critical theory are often more prescriptive and bottom-up. Those that endorse Ülrich Beck's notion of Risk Society often balance top down and bottom up and are more reflexive -although, all in all, they still show a general tendency towards prescriptiveness. Finally, papers assuming individualist or rational actor theories are generally descriptive (but they can be top down or bottom up, although often quantitative-based etc.). This grants plausibility to the existence of 'epistemic communities' (Adler and Haas 1992), composed of authors who work together, 
share institutional affiliations and/or use similar theoretical frameworks within their studies. A deeper enquiry on how these epistemic communities are built and operate within the literature on climate change will be needed in the future.

In summary, in the Chilean case, the literature on 'the social' of climate change displays two competing trends: on the one hand, it is inclined to become fragmented outside the scope of the cause-mitigation black box (or when attempting to overcome the mitigation-adaptation dichotomy); on the other, it tends to cluster along the lines of methodological distinctions traditionally contested within the social sciences. This, in turn, brings about the persistence of a disciplinary (and epistemic) division of work within what would otherwise be an interdisciplinary research field, hampering the potential for collaboration and exchange of knowledge. Also, reflexivity is quite scarce, with most of the work either focusing on purely instrumental description, or poorly grounded prescription. However, some work on more theoretically and normatively-informed issues has recently started to appear, both in qualitative and quantitative studies.

Based on such insights, it seems to us that the Chilean research community would benefit from more reflection on the conceptions, imaginaries and hypotheses that support the current division of work, and the epistemic and normative premises they entail. We argue that one initial, but fundamental step in such a path is to critically observe how social scientists (including the insights presented in this very paper!) construct 'the social' of climate change. This may permit, for starters, the identification of new research gaps and opportunities. Moreover, it would later help to delve into the question of how such a construction influences decision-making and climate policy.

Finally, it is important to point out the necessary limitations of a paper of this nature: since we are social scientists constructing a representation about how other social scientists construct representations of climate change, we could not avoid selfimplicating ourselves in the analysis. This also means that many of the choices we had to make in this study are, to some degree, arbitrary and depend on the stance we ourselves assume in relation to them. This cannot be avoided, but at least, we tried to make our choices as transparent as possible, in the hope of fostering a more reflexive understanding of the nature-society interdependency, and of the role (social) science plays both in observing and in reproducing such relations.

Acknowledgments This work has received funding provided by the following institutional grants: Comisión Nacional de Investigación Científica y Tecnológica (Chile), FONDAP Project No. 15110009 (all authors); National PhD Scholarship (Chile) No. CONICYT PFCHA/DOCTORADO NACIONAL/2017-21170615 (Marco Billi); Comisión Nacional de Investigación Científica y Tecnológica (Chile), FONDAP Project No. 15150003 (Gustavo Blanco); Comisión Nacional de Investigación Científica y Tecnológica (Chile), FONDECYT Grant No. 1160857 (Gustavo Blanco); Millennium Scientific Initiative (Chile), Project No. NS130017 (Marco Billi); Comisión Nacional de Investigación Científica y Tecnológica (Chile), FONDECYT Grant No. 11180824 (Anahí Urquiza).

Open Access This article is distributed under the terms of the Creative Commons Attribution 4.0 International License (http://creativecommons.org/licenses/by/4.0/), which permits unrestricted use, distribution, and reproduction in any medium, provided you give appropriate credit to the original author(s) and the source, provide a link to the Creative Commons license, and indicate if changes were made. 


\section{References}

Adler, Emanuel, and Peter M. Haas. 1992. Conclusion: Epistemic communities, world order, and the creation of a reflective research program. International Organization 46(1):367.

Agrawala, Shardul. 1998. Context and early origins of the intergovernmental panel on climate change. Climatic Change 39: 605-620.

Alexander, David E. 2013. Resilience and disaster risk reduction: an etymological journey. Natural Hazards and Earth System Sciences 13(11): 2707-2716.

Aufenvenne, Philipp, Heike Egner, and Kirsten Von Elverfeldt. 2014. On climate change research, the crisis of science and second-order science. Constructivist Foundations 10: 120-129.

Basset, Thomas J., and Charles Fogelman. 2013. Déjà vu or something new? The adaptation concept in the climate change literature. Geoforum 48: 42-53.

Beck, Ulrich. 2010. Climate for change, or how to create a green modernity? Theory, Culture \& Society 27(2-3): 254-266.

Bijker, Wiebe E., Thomas P. Hughes, and Trevor Pinch. 1987. The social construction of technological systems: New directions in the sociology and history of technology. Cambridge, Mass: MIT Press.

Billi, Marco, Anahí Urquiza, and Camilo Feres. 2017. Comunicación ambiental y proyectos energéticos renovables no convencionales. Análisis de contenido en medios de comunicación de masa chilenos. Revista Latina de Comunicación Social 72: 1218-1237.

Blanco, Gustavo, and María Ignacia Fuenzalida. 2013. La construcción de agendas científicas sobre cambio climático y su influencia en la territorialización de políticas públicas: reflexiones a partir del caso chileno. In Cambio climático, movimientos sociales y políticas públicas. Una vinculación necesaria, ed. Julio Postigo, 75-102. Santiago de Chile: ICAL.

Blanco, Gustavo, M. Griselda Günther, Ricardo A. Gutiérrez, and Javier G. Valencia. 2017. Introducción. Cambio ambiental global y políticas ambientales en América Latina. In La Política del Ambiente en América Latina: Una Aproximación Desde el Cambio Ambiental Global, eds. M.G. Günther and R. Gutiérrez, 15-36. Buenos Aires: UAM-Xochimilco/CLACSO.

Boillat, Sébastien, and Fikret Berkes. 2013. Perception and interpretation of climate change among Quechua farmers of Bolivia: Indigenous knowledge as a resource for adaptive capacity. Ecology and Society 18(4): 21.

Brondizio, Eduardo, Karen O’Brien, Xuermei Bai, Frank Biermann, Will Steffen, Frans Berkhout, et al. 2016. Re-conceptualizing the Anthropocene: A call for collaboration. Global Environmental Change 39: 318-327.

Bumpus, Adam G. 2011. The matter of carbon: Understanding the materiality of $\mathrm{tCO}_{2} \mathrm{e}$ in carbon offsets. Antipode 43(3): 612-638.

Burawoy, Michael. 2005. For public sociology. 2004 presidential address. American Sociological Review 70: 4-28.

CAIT (2014). Climate data explorer. Retrieved 9 February 2018: http://cait.wri.org.

Chernilo, Daniel. 2011. La pretensión universalista de la teoría social. Santiago de Chile: LOM Ediciones.

Chernilo, Daniel. 2017a. The question of the human in the Anthropocene debate. European Journal of Social Theory 20(1): 44-60.

Chernilo, Daniel. 2017b. Debating humanity. Towards a philosophical sociology. Cambridge: Cambridge University Press.

CONAMA. 2008. Plan de Acción Nacional de Cambio Climático (PANCC) 2008-2012. Santiago de Chile.

Cornell, Sarah, Frans Berkhout, J. Willemjin Tuinstra, David Tábara, Jill Jäger, Ilan Chabay, et al. 2013. Opening up knowledge systems for better responses to global environmental change. Environmental Science and Policy 28: 60-70.

CR2. 2015. Report to the Nation. The 2010-2015 mega-drought: A lesson for the future. Santiago: Universidad de Chile.

CR2. 2018. Informe final proyecto 'Simulaciones Climáticas regionales y marco de evaluación de la vulnerabilidad'. Santiago: Universidad de Chile.

de Olmos, Lioma Rossbach. 2011. Del monólogo científico a las pluralidades culturales: Dimensiones y contextos del Cambio Climático desde una perspectiva antropológica. In Perspectivas culturales del clima, ed. Astrid Ulloa, 55-82. Bogotá: ILSA 7 Universidad Nacional de Colombia. 
Demeritt, David. 2001. The construction of global warming and the politics of science. Annals of the Association of American Geographers 91(2): 307-337.

Driscoll, David, Afua Appiah-Yeboah, Philip Salib, and Douglas Rupert. 2007. Merging qualitative and quantitative data in mixed methods research: How to and why not. Ecological and Environmental Anthropology (University of Georgia) 3(1): 19-28.

Environment Ministry. 2015. Plan de Acción Nacional de Cambio Climático 2017-2022. Santiago de Chile: Gobierno de Chile.

Environment Ministry. 2016. Tercera Comunicación Nacional de Chile ante la Convención Marco de las Naciones Unidas sobre Cambio Climático. Santiago de Chile: Gobierno de Chile.

Escobar, Arturo. 2011. Epistemologías de la naturaleza y colonialidad de la naturaleza. Variedades de realismo y constructivismo. Cultura y Naturaleza. Bogotá: Jardín Botánico de Bogotá, José Celestino Mutis 65.

Estenssoro, Francisco J. 2007. Antecedentes para una historia del debate político en torno al medio ambiente: la primera socialización de la idea de crisis ambiental (1945-1972). Universum 22: 88-107.

Estenssoro, Francisco J. 2010. Crisis ambiental y cambio climático en la política global: un tema crecientemente complejo para América Latina. Universum 25: 57-77.

Feola, Giuseppe. 2015. Societal transformation in response to global environmental change: A review of emerging concepts. Ambio 44(5): 376-390.

Funtowicz, Silvio, and Jerome Ravetz. 2003. Post-normal science. International Society for Ecological Economics http://pdfs.semanticscholar.org/ce91/a2cf9b7e05411fb5b1b9276b9aaf565bffb2.pdf. Accessed 2 February 2018.

Giddens, Anthony. 2008. The politics of climate change. Policy Network 58: 156-162.

Giddens, Anthony. 2013. The constitution of society: Outline of the theory of structuration. New York: Wiley.

Harvey, David. 2005. A brief history of neoliberalism. Oxford: Oxford University Press.

Head, Lesley, and Chris Gibson. 2012. Becoming differently modern: Geographic contributions to a generative climate politics. Progress in Human Geography 36(6): 699-714.

Hirsch, Gertrude, David Bradley, Christian Pohl, Stephan Ristd, and Urs Wiesmann. 2006. Implications of transdisciplinarity for sustainable research. Ecological Economics 60: 119-128.

Hulme, Mike, and Martin Mahony. 2010. Climate change: What do we know about the IPCC? Progress in Physical Geography 34(5): 705-718.

IPCC. 2007. Climate Change 2007: impacts, adaptation and vulnerability: Contribution of Working Group II to the fourth assessment report of the Intergovernmental Panel on Climate Change. Cambridge: Cambridge University Press.

ISSC/UNESCO. 2013. World Social Science Report 2013: Changing Global Environments. OECD Publishing/Unesco Publishing.

Jasanoff, Sheila. 2010. A new climate for society. Theory, Culture and Society 27(2-3): 233-253.

Lahsen, Myanna. 2010. The social status of climate change knowledge: An editorial essay. WIREs Climate Change 1: 162-171.

Lampis, Andrea. 2013. La adaptación al cambio climático: el reto de las dobles agendas. In Cambio Climático, Movimientos Sociales y Políticas Públicas, ed. Julio Postigo, 29-50. Santiago de Chile: CLACSO/ICAL.

Latour, Bruno. 1987. Science in action: How to follow scientists and engineers through society. Cambridge, MA: Harvard University Press.

Latour, Bruno. 2007. Reassembling the social. An introduction to actor-network-theory. Oxford: Oxford University Press.

Lidskog, Rolf. 2001. The re-naturalization of society? Environmental challenges for sociology. Current Sociology 49: 113-136.

Liverman, Diana M. 2009. Conventions of climate change: constructions of danger and the dispossession of the atmosphere. Journal of Historical Geography 35: 279-296.

Monsalves-Gavilán, Pablo, Jimmy Pincheira-Ulbrich, and Félix Rojo Mendoza. 2013. Climate change and its effects on urban spaces in Chile: A summary of research carried out in the period 20002012. Atmosfera 26: 547-566.

Mooney, Harold A., Anantha Duraiappah, and Anne Larigauderie. 2013. Evolution of natural and social science interactions in global change research programs. Proceedings of the National Academy of Sciences 110(Supplement 1): 3665-3672. 
Moser, Susanne, Hanne Hackmann, and Françoise Calloids. 2013. Global environmental change changes everything. Key messages and recommendations. In World Social Science Report 2013: Changing Global Environments, ed. ISSC/UNESCO, 46-63. OECD Publishing/Unesco Publishing.

Nowotny, Helga. 2003. Democratising expertise and socially robust knowledge. Science and Public Policy 30: 151-156.

O'Brien, Karen. 2012. Global environmental change II: From adaptation to deliberate transformation. Progress in Human Geography 36: 667-676.

Orlowe, Ben, Arun Agrawal, and Maria C. Lemos. 2012. Cool heads for a hot world-Social sciences under a changing sky. Global Environmental Change 22: 329-331.

Postigo, Julio C. 2013. Cambio climático, movimientos sociales y políticas públicas: una vinculación necesaria. Santiago de Chile: CLACSO.

Ragin, C. 2000. Fuzzy-set social science. London: The University of Chicago Press.

Rödder, Simone. 2017. The Climate of Science-Art and the Art-Science of the Climate: Meeting Points, Boundary Objects and Boundary Work. Minerva 55(1): 93-116.

Schipper, E. Lisa. 2006. Conceptual history of adaptation in the UNFCCC process. RECIEL 15(1): 82-92.

Smit, Barry, and Johanna Wandel. 2006. Adaptation, adaptive capacity and vulnerability. Global Environmental Change 16: 282-292.

Spangenberg, Joachim H. 2011. Sustainability science: A review, an analysis and some empirical lessons. Environmental Conservation 38: 275-287.

Star, Susan L., and James Griesemer. 1989. Institutional ecology, "Translations" and boundary objects: Amateurs and professionals in Berkeley's Museum of Vertebrate Zoology, 1907-39. Social Studies of Science 19: 387-420.

Star, Susan L. 2010. This is not a boundary object: Reflections on the origin of a concept. Science, Technology, and Human Values 35: 601.

Stephan, Benjamin, and Matthew Paterson. 2012. The politics of carbon markets: An introduction. Environmental Politics 21(4): 545-562.

Swyngedouw, Erik. 2013. The non-political politics of climate change. ACME: An International Journal for Critical Geographies 12(1): 1-8.

Team, Victoria, and Lenore Manderson. 2011. Social and public health effects of climate change in the "40 South". WIREs Climate Change 2(6): 902-918.

Ulloa, Astrid. 2011a. Construcciones culturales sobre el clima. In Perspectivas culturales del clima, ed. Astrid Ulloa, 33-54. Bogotá: ILSA 7 Universidad Nacional de Colombia.

Ulloa, Astrid. 2011b. Políticas globales de cambio climático: nuevas geopolíticas del conocimiento y sus efectos en territorios indígenas. In Perspectivas culturales del clima, ed. Astrid Ulloa, 477-493. Bogotá: ILSA 7 Universidad Nacional de Colombia.

UNFCCC. 2016. Paris agreement. United Nations Treaty Collection.

Victor, David. 2015. Climate change: Embed the social sciences in climate policy. Nature 520: 27-29.

Weart, Spencer R. 2010. The idea of anthropogenic global climate change in the 20th century. WIREs Climate Change 1(1): 67-81.

White, Lynn. 1967. The historical roots of our ecological crisis. Science 155(3767): 1203-1207.

Wiek, Arnim, Barry Ness, Petra Schweizer-Ries, Fridolin S. Brand, and Francesca Farioli. 2012. From complex systems analysis to transformational change: A comparative appraisal of sustainability science projects. Sustainability Science 7: 5-24.

Yearley, Steven. 2009. Sociology and climate change after Kyoto: What roles for social science in understanding climate change? Current Sociology 57: 389-405.

Zehr, Stephen. 2015. The sociology of global climate change. WIREs Climate Change 6(2): 129-150.

Publisher's Note Springer Nature remains neutral with regard to jurisdictional claims in published maps and institutional affiliations. 